Article

\title{
Former Land Use and Host Genotype Influence the Mycorrhizal Colonization of Poplar Roots
}

\section{Felicia Gherghel ${ }^{1, *}$, David Behringer ${ }^{2}$, Stefanie Haubrich ${ }^{\mathbf{1}}$, Maren Schlauß ${ }^{\mathbf{1}}$, Christina Fey-Wagner ${ }^{3}$, Karl-Heinz Rexer ${ }^{1}$, Alwin Janßen ${ }^{3}$ and Gerhard Kost ${ }^{1}$}

1 Systematic Botany and Mycology, University of Marburg, Karl-von-Frisch-Str. 8, 35032 Marburg, Germany; E-Mails: Stefanie.Haubrich@gmx.de (H.S.); maren.schlauss@gmail.com (S.M.); rexer@staff.uni-marburg.de (R.K.-H.); kost@staff.uni-marburg.de (K.G.)

2 Conservation Biology, University of Marburg, Karl-von-Frisch-Str. 8, 35032 Marburg, Germany; E-Mail: david.behringer@uni-marburg.de (B.D.)

3 Department of Forest Gene Resources, Nordwestdeutsche Forstliche Versuchsanstalt (NW-FVA), Hann. Münden, 34346, Germany; E-Mails: alwin.janssen@nw-fva.de (J.A.); christina.fey-wagner@nw-fva.de (F.-W.C.)

* Author to whom correspondence should be addressed; E-Mail: fgherghel@gmail.com; Tel.: +49-6421-2822-077; Fax: +49-6421-2822-092.

External Editor: Douglas L. Godbold

Received: 31 October 2014; in revised form: 17 November 2014 / Accepted: 26 November 2014 / Published: 4 December 2014

\begin{abstract}
The present paper analyses the community structure of ectomycorrhiza (ECM) and arbuscular mycorrhiza (AM) fungi associated with seven different poplar clone types growing in a patch system on soil from four different former land use types, originating from spruce forest, poplar stand, grassland and cornfield. We determined the extent to which ECM and AM play a role on the studied factors (genotype, former land use type and host growth). The diversity of ECM and AM fungal communities was estimated by morphological and molecular analyses of the $18 \mathrm{~S}$ and ITS of the rDNA genes. Fifteen ECM fungal taxa and four AM groups were distinguished in the roots of the poplars grown for 18 months on soil originating from the respective land use types. The poplar clones showed significantly different rates of shoot length and AM colonization, especially concerning the occurrence of Glomus intraradices and Scutellospora sp. Populus deltoides had significantly higher Scutellospora sp. abundance. Although ECM abundance and
\end{abstract}


diversity was high, no significant differences between the different land use types was found. However, some ECM fungi like Paxillus involutus, Laccaria proxima and Laccaria tortilis showed significant preferences for specific land use types. Our findings suggest that both factors, former land use type and poplar genotype, are important determinants of mycorrhizal colonization of the host plants.

Keywords: arbuscular mycorrhiza; ectomycorrhiza; poplar shoot length; land use type; 18S rDNA

\section{Introduction}

Poplars are among the superior hardwood trees used as a source of wood biomass for bioenergy production, plywood confection, phytoremediation and, owing to their superior biomass productivity, they have been used for short-rotation coppice cultures [1]. Genetic variability in terms of tree growth, agronomic traits (e.g., plant height, time to maturity), and timber quality is found within the Populus genus, particularly among the interspecific hybrids [2,3]. Many breeding programs have thus been developed with an ultimate goal being the selection of the most productive genotypes.

Mycorrhizas play an essential role in ecosystem functioning by providing mineral nutrition to autotrophic vegetation and tolerance to various abiotic and biotic stress factors. The establishment, growth, and survival of poplar trees in the field depend strongly on colonization by mycorrhizal fungi. For most trees in temperate and boreal forests, ectomycorrhiza (ECM) is the dominant mycorrhiza type that involves many lineages of fungi mostly belonging to Basidiomycota and Ascomycota $[4,5]$. Although most plant species generally form only one of the several possible types of mycorrhizal associations, poplars are among the few commercially important trees that form tripartite symbiotic associations with ECM and AM fungi [6,7]. Whereas some studies consider that the colonization by AM versus ECM fungi is influenced by the local soil environment [8,9], other studies also suggest that host plant genetics may play a role in determining the dominant mycorrhizal type in dually colonized hosts [10-14]. Neville et al. [15] described that during the juvenile stage of growth, the main colonizers of poplar roots are AM fungi, which are subsequently replaced by ECM fungi.

The diversity of ECM fungal communities can be estimated by morphological and molecular analyses of mycorrhizal root tips from below ground. With the help of the field ECM molecular identification techniques, between 12 and 54 species of ECM fungi were detected on different species of poplar [16]. The range of ECM colonization of poplars is very broad and has been found to be influenced by environmental factors or ECM inoculum potential of the surrounding area and less by host genetics $[15,17,18]$.

AM fungi cannot be identified with the help of microscopic methods because of a lack of diagnostic features of their intra- and extraradical hyphae. These fundamental problems of identification rendered the study of their diversity, particularly in their natural habitat the soil and roots, extremely difficult. Nowadays, AM fungi can be detected using five pairs of taxon-specific primers targeted to the 18S rDNA genes [19]. These primers enabled the recognition of AM fungi in five distinct groups: Glomus mosseae, G. intraradices, G. claroideum, G. hoi, and Scutellospora spp. [19]. 
Less is known about the influence of genotype and soil characteristics on poplar roots and the structure of their ECM and AM fungi community in the juvenile stage of the tree. In the present study we focused on the analysis of the community structure of ECM and AM fungi associated with seven poplar clones growing on soils originating from four different land use types in a patch culture system. Given that the studied poplar clones represented different species and hybrids grown in soils from different former land use types, we hypothesized that clones have different capacities of growth on different soil substrates and would significantly shape the ECM and AM communities.

The understanding of the roles of environmental factors and host genetics in determining the relative mycorrhizal colonization of dually colonized plant species may provide valuable insights into the functioning and importance of these mutualisms for renaturation programs.

\section{Experimental Section}

\subsection{Plant Material, Study Site and Sample Collection}

In order to find out which clone type grows best on the different former land use types we analyzed seven poplar clone types: P. nigra (clone Fritzlar 2 Maserpappel) $(=\mathrm{C} 1)$, P. deltoides $(=\mathrm{C} 2)$, P. nigra $\times$ P. maximowiczii (clone Max 3) $(=\mathrm{C} 3)$, P. trichocarpa (=C4), P. maximowiczii (=C5), $P$. canadensis (clone ROBUSTA) $(=\mathrm{C} 6)$ and $P$. maximowiczii $\times$ P. trichocarpa (clone Hybrid 275 (NE42)) (=C7). Cuttings from these seven clone types were provided by NW-FVA (Northwest German Forestry Research Institute) in Hannoversch Münden, Germany. Two individuals from each clone type were randomly placed in a patch containing soil originating from one of four different land use types: cornfield $(\mathrm{C})$, grassland $(\mathrm{G})$, poplar stand $(\mathrm{P})$ and spruce forest $(\mathrm{S})$. To characterize the different soils we measured the respective $\mathrm{pH}$ (measured on $\mathrm{CaCl}_{2}$ and $\mathrm{H}_{2} \mathrm{O}$ ) as well as the concentration of essential elements (C, N, P and S). The 56 poplar clones (two individuals from every clone type in each of the four patches containing different soil) were grown until October 2010, when sampling for $\mathrm{AM}$ and ECM analyses was conducted on the 18 months old individuals. For this purpose the entire root system was sampled. Before collecting root samples, the shoot length was measured for each individual. Following, the surface layer (leaf litter) was removed and roots were sampled by taking two fine root systems per tree. Samples were wrapped in plastic bags and stored at $4{ }^{\circ} \mathrm{C}$ until further procedures. For analyzing the occurrence of mycorrhizas (ECM and AM), roots were washed and carefully cleaned under a stereoscopic microscope. Two $5 \mathrm{~cm}$ roots of each clone were used for AM analyses, while the rest was kept at $-20^{\circ} \mathrm{C}$ for the examination of ECM in fresh roots.

\subsection{Ectomycorrhizas (ECM)}

Each root system was searched for ECM root tips for $20 \mathrm{~min}$. The root tips were categorized in morphotypes (=ectomorphotypes) according to ramification and shape, mantle texture and color, as well as presence and color of emanating hyphae and/or rhizomorphs [20]. The individual colonized root tips were kept in $1.5 \mathrm{~mL}$ plastic tubes and dried at $30{ }^{\circ} \mathrm{C}$ for 24 hours to perform molecular analyses. We made no attempt to relate morphotypes to abundance until molecular analysis was complete. Thus, each morphotype sample was treated separately in a subsequent molecular typing and 
pooled for abundance calculation only after the molecular analysis indicated that ECM morphotypes were identical.

\subsection{Arbuscular Mycorrhiza (AM)}

Occurrence of AM was analyzed for two $5 \mathrm{~cm}$ root samples per clone. Root samples were stained using the modified method of [21]. The $5 \mathrm{~cm}$ long pieces of root were separated and placed in one embedding cassette (Rotilabo Roche, Mannheim, Germany). The embedding cassettes were boiled in a $10 \% \mathrm{KOH}$ solution for $10 \mathrm{~min}$. Then the samples were rinsed several times with water and boiled in a $3 \% \mathrm{H}_{2} \mathrm{O}_{2}$ solution for 5-10 min. The samples were again rinsed thoroughly with water and boiled in a $5 \%$ solution of ink and acetic acid for $5 \mathrm{~min}$ [21]. Once stained, the $5 \mathrm{~cm}$ root pieces were divided in 10 fragments of $5 \mathrm{~mm}$ length, mounted on a microscope slide and examined under a light microscope according to [22]. The method allowed a good overview of the rate of colonization, respectively the presence of arbuscules, vesicles or hyphae. Additionally, the exact number of vesicles and arbuscules was determined so that a statistical evaluation could be done.

\subsection{Molecular Identification of ECM}

ECM fungi were identified by sequencing the internal transcribed spacer of the DNA (ITS rDNA) after PCR amplification. All root types were used for ITS amplification. The ITS regions were amplified by a NESTED PCR using the universal primer pair NSI1 and NLB4 for a first PCR reaction and the ITS1F/ITS4 for the second reaction [23]. The $20 \mu \mathrm{L}$ reaction volume contained ultra-pure water, $2 \times$ PCR reaction buffer, $0.5 \mu \mathrm{M}$ of each primer, 5 units $/ \mu \mathrm{L}$ Phire polymerase (Phire Plant Direct PCR Kit, Finnzymes, Thermo Scientific, Germany), and ECM roots as template DNA. For this, the ECM roots were cut into tiny pieces. The PCR program for the first reaction consisted of initial denaturation at $98{ }^{\circ} \mathrm{C}$ for $5 \mathrm{~min}$, followed by 28 cycles of denaturation at $98{ }^{\circ} \mathrm{C}$ for $5 \mathrm{~s}$, annealing at $54{ }^{\circ} \mathrm{C}$ for $5 \mathrm{~s}$ and extension at $72{ }^{\circ} \mathrm{C}$ for $20 \mathrm{~s}$, and culminating in a final extension at $72{ }^{\circ} \mathrm{C}$ for $1 \mathrm{~min}$. The first NSII/NLB4PCR was diluted to a final concentration of approximately $2 \mathrm{ng} / \mu \mathrm{L}$ DNA. The second reaction consisted of initial denaturation at $98{ }^{\circ} \mathrm{C}$ for $5 \mathrm{~min}$, followed by 30 cycles of denaturation at $98{ }^{\circ} \mathrm{C}$ for $5 \mathrm{~s}$, annealing at $52{ }^{\circ} \mathrm{C}$ for $5 \mathrm{~s}$ and extension at $72{ }^{\circ} \mathrm{C}$ for $20 \mathrm{~s}$, and culminating in a final extension at $72{ }^{\circ} \mathrm{C}$ for $1 \mathrm{~min}$. PCR products were digested by the restriction endonucleases RSA1 (Fisher Scientific GmbH, Schwerte, Germany). The reaction was carried out in a total volume of $20 \mu \mathrm{L}$ with $1 \mu \mathrm{L}$ enzyme-specific 10x Tangobuffer, 2 units of the respective restriction enzyme, $5 \mu \mathrm{L}$ of PCR product and $12.5 \mu \mathrm{L}$ aqua bidest. The incubation temperature was set at $37{ }^{\circ} \mathrm{C}$ for 6 hours or overnight, and DNA fragments were separated on a 1.8\% agarose gel (Invitrogen, Darmstadt, Germany). Samples representing different RFLP groups were sequenced. Prior to sequencing, target fragments were purified using the QIAquick ${ }^{\circledR}$ PCR Purification Kit (Qiagen, Hilden, Germany). Fragments were sequenced by LGC Genomics (Berlin, Germany) using ABI 3730 XL platforms for traditional Sanger sequencing. The sequences were compared using BLASTn to sequences in the NCBI [24] and UNITE [25] databases. 


\subsection{Molecular Detection of AM}

For the characterization of the AM fungi abundance and diversity on poplar samples we used microscopic methods and four pairs of taxon-specific primers targeting the 18S rDNA genes [19]. The ITS regions were amplified by a NESTED PCR using the universal primer pair GEOA1 and ART4 [26] for a first PCR reaction and the four pairs of taxon-specific primers targeting the 18S rDNA genes (GmF-GmR Glomus mosseae group, GiF-GiR Glomus intraradices group, GhF-GhR Glomus hoi, SsF-SsR Scutellospora spp. [19]) for the second reaction. The $20 \mu \mathrm{L}$ reaction volume contained ultra-pure water, $2 \times$ PCR reaction buffer, $0.5 \mu \mathrm{M}$ of each primer, 5 units $/ \mu \mathrm{L}$ Phire polymerase (Phire Plant Direct PCR Kit, Finnzymes, Thermo Scientific, Schwerte, Germany), and AM roots as template DNA. The AM roots were cut into dot-sized pieces. The PCR program for the first reaction consisted of initial denaturation at $98{ }^{\circ} \mathrm{C}$ for $5 \mathrm{~min}$, followed by 28 cycles of denaturation at $98{ }^{\circ} \mathrm{C}$ for $5 \mathrm{~s}$, annealing at $62{ }^{\circ} \mathrm{C}$ for $5 \mathrm{~s}$ and extension at $72{ }^{\circ} \mathrm{C}$ for $20 \mathrm{~s}$, and culminating in a final extension at $72{ }^{\circ} \mathrm{C}$ for $1 \mathrm{~min}$. The first GEOA1/ART4 PCR was diluted to a final concentration of approximately $2 \mathrm{ng} / \mu \mathrm{L}$ DNA. The second reaction consisted of initial denaturation at $98{ }^{\circ} \mathrm{C}$ for $5 \mathrm{~min}$, followed by 30 cycles of denaturation at $98{ }^{\circ} \mathrm{C}$ for $5 \mathrm{~s}$, annealing at $60{ }^{\circ} \mathrm{C}$ for $5 \mathrm{~s}$ and extension at $72{ }^{\circ} \mathrm{C}$ for $20 \mathrm{~s}$, and culminating in a final extension at $72{ }^{\circ} \mathrm{C}$ for $1 \mathrm{~min}$ ). Samples representing the different AM groups were sequenced using the methods described for ECM.

\subsection{Statistical Analyses}

The number of ECM species was assessed by species accumulation curves with first-order jackknife estimation and 100 permutations. The ECM communities of the soils from different land use types, as well as the clone types were described by estimating species richness, Shannon's diversity index (H') and Pieolou's evenness index (J). All community parameters were calculated using the R package vegan [27]. To test for dependencies between the occurrences of the different mycorrhizal species, Pearson correlation coefficients on the ranks were calculated for each species combination. To analyze the effect of former land use type on mycorrhizal colonization and poplar shoot length a simple linear mixed model (LMM) with former land use type as fixed effect and clone type as random effect with a Tukey's honest significant difference (HSD) post-hoc test was calculated. Our study was in the form of an unreplicated factorial design with the former land use types representing blocks wherein each clone type was represented once in a randomized order. Hence we calculated LMMs for each response variable with clone type as fixed effect and former land use type as random effect to analyze the effect of the clone type while accounting for the treatment effect of the former land use type. For data that could not be transformed $(\log 10+1$ or square root) to fulfil the requirements of a LMM, an unreplicated two-way ANOVA on the ranks with a subsequent Tukey's HSD test was performed. All LMM's incorporated a restricted maximum likelihood approach (REML) and were implemented using the lme4 package in R [28]. All post-hoc tests were conducted with the R package multcomp [29]. 


\section{Results and Discussion}

\subsection{Richness and Diversity of Mycorrhiza}

Dual mycorrhizal colonization by ECM and AM fungi was observed in the roots of all poplar clones in all soils from different former land use types. The species accumulation curves of the ECM fungi nearly reached an asymptote for all samples on all study sites (Figure 1).

Figure 1. Species accumulation curves for ECM fungal species in poplar root tips on the four investigated former land use type.

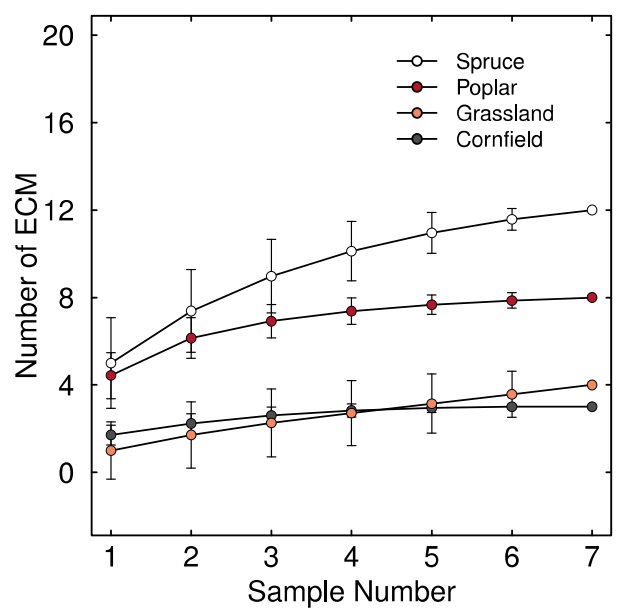

The highest ECM diversity was found for the poplars grown in S-soil, followed by the ECM diversity on P-, G- and C-soil. The highest value of the Shannon's ECM diversity index was in $\mathrm{P}$ - and S-soil and lower in the C- and G-soil, whereas between the clones the values were more constant (Table 1).

Table 1. Mean values of species richness and the ecological indexes of ectomycorrhizal communities associated with the seven poplar clone types grown in the four different former land use types.

\begin{tabular}{cccc}
\hline Soil and Clone & Species Richness & Shannon's Diversity Index & Evenness Index \\
\hline S & 12 & 3.15 & 1.27 \\
P & 8 & 3.24 & 1.56 \\
G & 4 & 1.83 & 1.32 \\
C & 3 & 2.26 & 2.06 \\
C1 & 10 & 2.37 & 1.03 \\
C2 & 8 & 1.87 & 0.90 \\
C3 & 6 & 2.18 & 1.22 \\
C4 & 8 & 2.31 & 1.11 \\
C5 & 8 & 2.07 & 1.00 \\
C6 & 8 & 2.35 & 1.13 \\
C7 & 8 & 2.19 & 1.05 \\
\hline
\end{tabular}

The identified ECM fungi belonged to six families: five of Basidiomycota: Cortinariaceae, Inocybaceae, Hydnangiaceae, Paxillaceae and Sebacinaceae and one of Ascomycota: Pezizaceae 
(Table 2). The identified AM fungi belonged to four groups: Glomus intraradices, G. mossae, G. hoi and Scutellospora sp. G. intraradices was the most abundant AM group (Table 2).

Table 2. Identification of ECM and AM associated with the seven poplar clone types (according to NCBI [24] and UNITE [25] databases).

\begin{tabular}{ll}
\hline Mycorrhizal Taxon & GenBank Accesion Number \\
\hline Inocybe curvipes & KJ591031, KJ591036, KJ591039 KJ591030, KJ591037, KJ591038 \\
Paxillus involutus & KJ591032 \\
Hebeloma sacchariolens & KJ624710 \\
Hebeloma vaccinum & KJ591035 \\
Laccaria tortilis & KJ591042, KJ591043, KJ591044 \\
Laccaria proxima & KJ591040, KJ591041 \\
Laccaria bicolor & KJ624712 \\
Pezizales (1) & KJ591033 \\
Pezizaceae (2) & KJ591045 \\
Pezizales (3) & KJ591034 \\
Pezizales (4) & KJ624711 \\
Pezizales (5) & KJ624714 \\
Sebacinales & KJ624715 \\
Meliniomyces & KJ624713 \\
Glomus mossae & KJ591046 \\
Glomus intraradices & KJ591047 \\
Glomus hoi & KJ591049 \\
Scutellospora sp. & KJ591048 \\
\hline
\end{tabular}

During the early stage of growth, the main colonizers of poplar roots are AM fungi, which are subsequently replaced by ECM fungi [15]. The ratio between ECM and AM colonization of poplars is showing a broad range and has been found to be influenced by environmental factors and host genetics [10-14]. Plant genotypes have been shown to differ in both their ability to form mycorrhiza, and in the relative benefit received from this mycorrhizal colonization [9,30]. In our study, all the 18 months old poplar clones grown on the four soils from different land use types were dually colonized by AM and ECM fungi. The colonization rates were variable between the different soils.

\subsection{Influence of the Former Land Use Type}

The significant variability of the colonization rate of AM, the shoot length, as well as the colonization by AM hyphae, number of vesicles, G. mossae, G. intraradices, Scutellospora sp., P. involutus, L. tortilis and L. proxima was observed between the different soils (Table 3). Significant differences between groups always refer to the corresponding Tukey post-hoc test $(p<0.05)$. 
Table 3. ANOVA table of the LMMs showing the fixed effect of former land use type (C-, G-, P- and S-soil) on the different response variables while accounting for clone type as a random effect; degrees of freedom $(d f)$ : three between groups and 18 within groups.

\begin{tabular}{cccc}
\hline Response Variable & Transformation & $\boldsymbol{F}$-Value & $\boldsymbol{p}$-Value \\
\hline AM & - & 8.05 & 0.0013018 \\
ECM & - & 0.85 & 0.4867 \\
Shoot length & - & 55.86 & $<0.001$ \\
AM hyphae & squared $^{\text {a }}$ & 9.77 & $<0.001$ \\
Vesicles & rank $^{\text {a }}$ & 7.20 & 0.002245 \\
Arbuscules & rank $^{\text {a }}$ & 0.58 & 0.634039 \\
Glomus mossae & - & 3.16 & 0.04999 \\
Glomus intraradices & - & 4.36 & 0.01787 \\
Glomus hoi & - & 1.45 & 0.261 \\
Scutellospora sp. & - & 28.3 & $<0.001$ \\
Paxillus involutus & rank $^{\text {a }}$ & 36.67 & $<0.001$ \\
Laccaria tortilis & $\log 10+1$ & 6.31 & 0.0041 \\
L. proxima & rank $^{\text {a }}$ & 6.99 & 0.00258 \\
\hline
\end{tabular}

a A two-factorial ANOVA was calculated on the ranks; - No transformation performed.

The colonization rate of AM was significantly higher for the poplars grown in the G-soil than in the P-, or S-soil (Figure 2a, Table 3). Furthermore, the colonization rate of AM of the poplars grown in the $\mathrm{C}$-soil was significantly higher than those grown in the P-soil. No significant differences of the colonization rate of AM were found between the poplars grown in P- and S-soil. Although the poplar clones grown on the P- and S-soil hosted the highest number of ECM fungi, compared with those grown in the C- and G-soils, the differences between all four soils were not significant (Figure 2b, Table 3). The poplar shoot height in S-soil was significantly lower than in all other soils (Figure 2c, Table 3). The S-soil presented also the lowest $\mathrm{pH}, \mathrm{N}$ and $\mathrm{P}$ content (see Table 4). For a successful symbiosis, both partners must be able to withstand the lower $\mathrm{pH}$ during all stages of colonization. Our results show that the observed abundance of ECM types was lower than in slightly acidic substrates. Jumpponen et al. [31] discussed that the dynamics of the fungal community may be correlated with the soil characteristics, as the fungal communities are sensitive to macronutrients and $\mathrm{pH}$ but also to metal (oid) enrichment.

Table 4. Soil chemical characteristics $(\mathrm{g} / \mathrm{kg})$ and $\mathrm{pH}$ of the four land use sites.

\begin{tabular}{ccccccc}
\hline Former Land Use Type & $\mathbf{C}$ & $\mathbf{N}$ & $\mathbf{P}$ & $\mathbf{S}$ & $\mathbf{p H}\left(\mathbf{C a C l}_{\mathbf{2}}\right)$ & $\mathbf{p H}\left(\mathbf{H}_{\mathbf{2}} \mathbf{O}\right)$ \\
\hline Cornfield & 12.94 & 1.32 & 0.67 & 0.19 & 5.07 & 5.81 \\
Grassland & 10.13 & 0.95 & 0.58 & 0.13 & 5.59 & 6.23 \\
Poplar stand & 18.72 & 1.74 & 0.58 & 0.24 & 5.49 & 6.11 \\
Spruce forest & 47.70 & 2.62 & 0.36 & 0.34 & 3.50 & 4.12 \\
\hline
\end{tabular}


Figure 2. The degree of AM colonization (\% in $10 \mathrm{~cm}$ root length) (a); ECM colonization (\% in 20 min sampling) (b); and shoot length (c) of seven poplar clones in the four different land use types $(\mathrm{C}=$ cornfield, $\mathrm{G}=$ grassland, $\mathrm{P}=$ poplar soil, $\mathrm{S}=$ spruce soil $)$. The shoot length and the rate of AM colonization varied significantly among sites and poplar clones. $(\mathrm{C} 1=P$. nigra (clone Fritzlar 2 Maserpappel); $\mathrm{C} 2=P$. deltoids; $\mathrm{C} 3=$. nigra $\times$ $P$. maximowiczi (clone $\mathrm{Max} 3$ ); $\mathrm{C} 4=P$. trichocarpa; $\mathrm{C} 5=P$. maximowiczii $\mathrm{C} 6=P$. canadensis $($ clone ROBUSTA); $\mathrm{C} 7=P$. maximowiczii $\times P$. trichocarpa (clone Hybride 275 (NE42)).
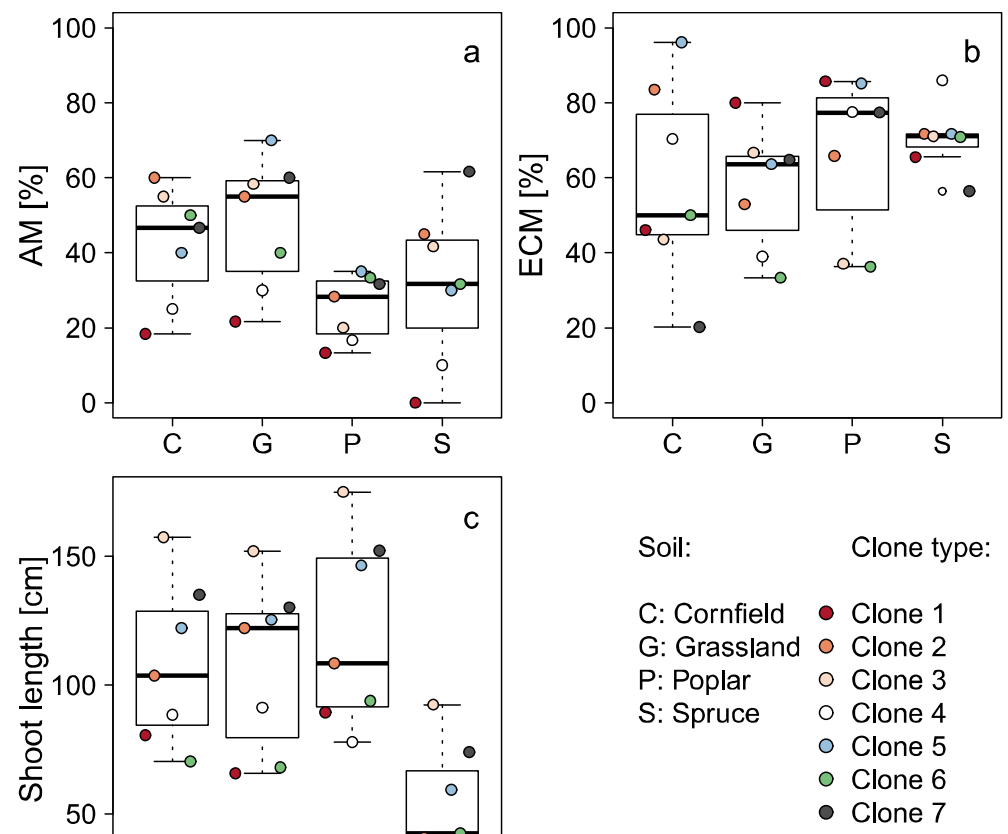

The amount of vesicles was significantly higher in the G-soil than in P- and S-soil and correspondingly higher in the C-soil than in the P-soil (Figure 3a, Table 3). Also, the occurrence of AM hyphae was significantly higher in the G-soil than in P- and S-soil (Figure 3c). The occurrence of AM hyphae was significantly higher for the poplars grown in the C-soil compared with that from the P-soil.

The fact that the poplars grown on field soils ( $\mathrm{C}$ - and G-soil) presented the highest colonization rates of AM fungi compared with the poplars grown on the forest soils (P- and S-soil), might be due to high abundance and/or diversity of AM fungi in these land use types or because of the lack of ECM fungi which might have out-competed AM fungi in forest soils in a stronger way. The last statement is strengthened because the forest soils gave rise to a higher abundance and diversity of ECM fungi, although the differences between all four types of soils were not significant. Concerning the shoot length of the poplars we found significant differences between the clones grown on the four different soils, which were highly correlated with the AM abundance, particularly with the amount of vesicles. There was no significant correlation of the shoot length of the poplars with the ECM abundance or diversity. This enables us to conclude that AM abundance plays an important role during poplar establishment and juvenile growth. So it was not surprising that poplars grown in the S-soil had the lowest shoot length and the lowest colonization rate of AM. 
Figure 3. The degree of colonization by vesicles (a); arbuscules (b); and AM hyphae (c) (\% in $10 \mathrm{~cm}$ root length) of seven poplar clones in the four different land use types $(\mathrm{C}=$ cornfield, $\mathrm{G}=$ grassland, $\mathrm{P}=$ poplar soil, $\mathrm{S}=$ spruce soil). The number of vesicles and arbuscules varied significantly among sites and poplar clones. $(\mathrm{C} 1=P$. nigra (clone Fritzlar 2 Maserpappel); $\mathrm{C} 2=P$. deltoids $; \mathrm{C} 3=P$. nigra $\times P$. maximowiczi $($ clone Max 3$)$; $\mathrm{C} 4=P$. trichocarpa; $\mathrm{C} 5=P$. maximowiczii $\mathrm{C} 6=P$. canadensis (clone ROBUSTA); $\mathrm{C} 7=$ P. maximowiczii $\times$ P. trichocarpa $($ clone Hybride $275(\mathrm{NE} 42)$ ).
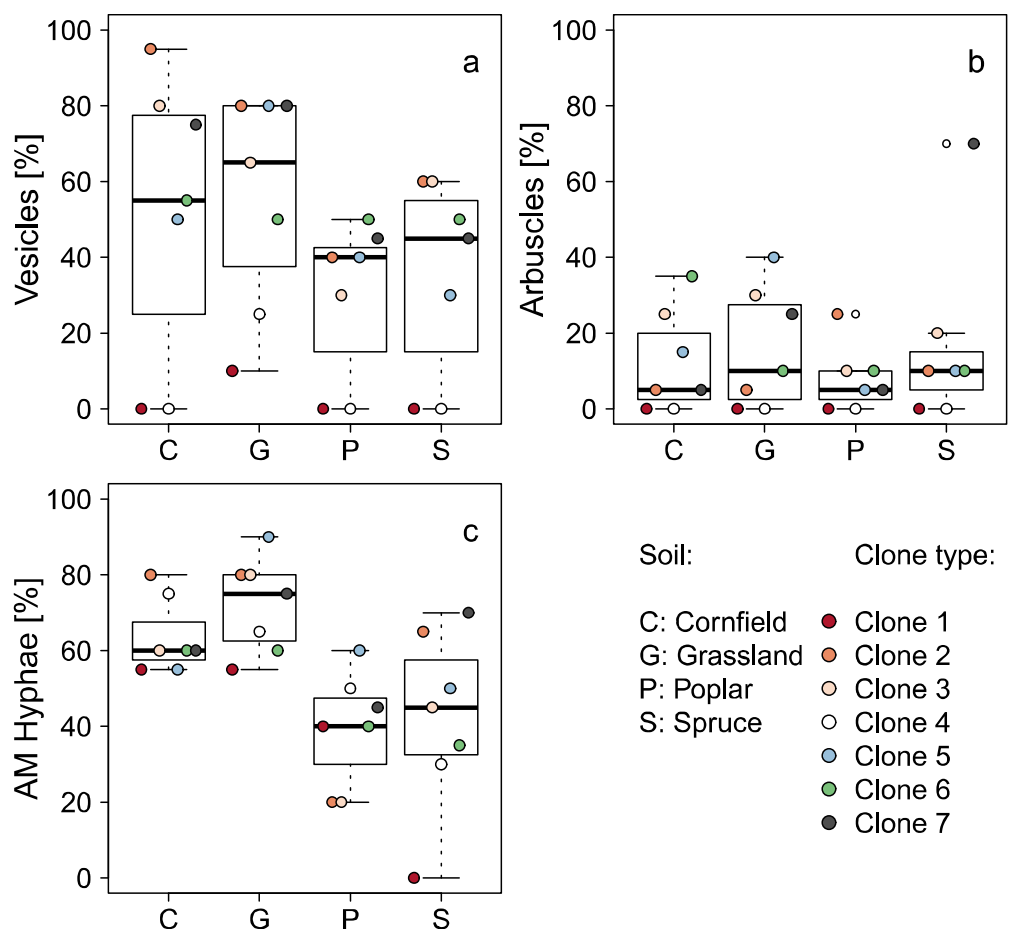

$$
\begin{array}{lll}
\text { Soil: } & & \text { Clone type: } \\
\text { C: Cornfield } & \circ & \text { Clone } 1 \\
\text { G: Grassland } & \circ & \text { Clone } 2 \\
\text { P: Poplar } & \circ & \text { Clone } 3 \\
\text { S: Spruce } & \circ & \text { Clone 4 } \\
& \circ \text { Clone } 5 \\
& \circ \text { Clone } 6 \\
& \circ \text { Clone } 7
\end{array}
$$

Looking at the ECM diversity, one might have expected that former forest soils would lead to an ECM community with higher diversity than former field soils. However the differences were not significant. But there were significant differences between single fungal species. The poplars grown on the C-soil were mostly colonized by $P$. involutus, whereas in the P-soil L. proxima was highly abundant; L. tortilis on the other hand was mostly present in the P- and S-soil (Figure 4). The Ascomycetes were found on the root systems of poplars grown on P- and S-soil (Figure 4).

The presence of $P$. involutus in C-soil can only be explained by the establishment of the fungus via spores from the air and the preference for the low $\mathrm{pH}$. This would easily have been accepted, if P. involutus would have been highly abundant in G-soil also. But in G-soil the fungus with the highest abundance was Inocybe curvipes. Due to this, it might be expected that these two fungal species have a kind of antagonistic effect on each other.

In a pot experiment Baum et al. [32] reported that whereas inoculation of the balsam poplar clone (P. trichocarpa cv. Weser 6) by L. bicolor reduced the AM spore density, P. involutus had no significant effect on the AM spore density in the soil. The fact that we found lower AM abundance in the P- and S-soil could be attributed to the competitive character of L. tortilis and L. proxima, whereas in C-soil, where P. involutus was most dominant, AM fungi were not reduced in the same way. Thus we can conclude that although in early stage of establishment the poplars prefer AM fungi, in the subsequent time, ECM fungi establish and tolerate or replace AM fungi. 
Figure 4. ECM diversity ((\%) in 20 min sampling) in the four soils originating from different former land use types $(\mathrm{C}=$ cornfield, $\mathrm{G}=$ grassland, $\mathrm{P}=$ poplar soil, $\mathrm{S}=$ spruce soil $)$.
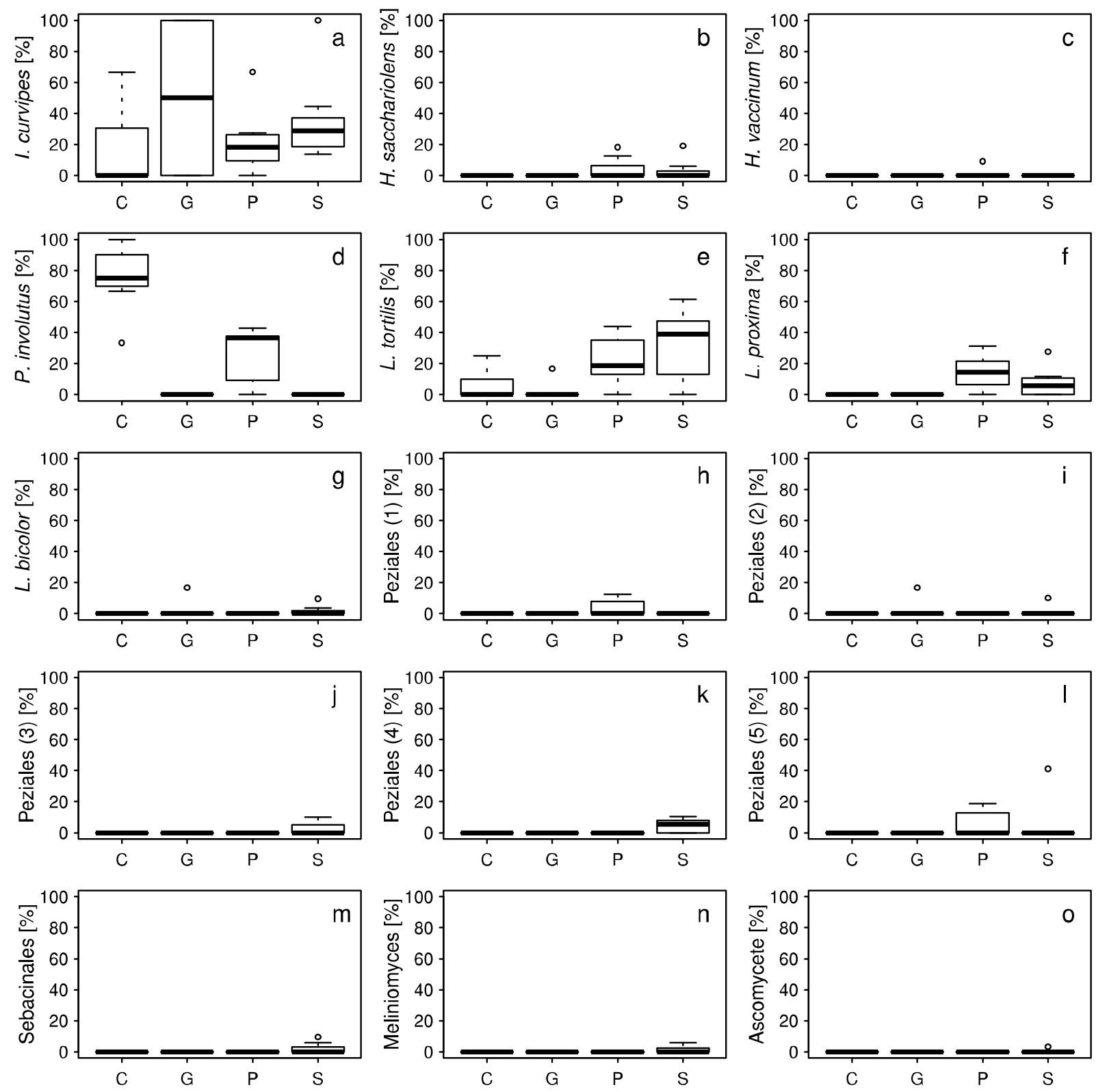

Glomus intraradices was the most abundant AM group. The poplars grown in S-soil showed the lowest abundance of the G. intraradices group compared with C-, G- and P-soil (Figure 5b) and also showed the lowest shoot length (Figure 2c). For the G. mosseae (Figure 5a) and G. hoi group (Figure 5c) no significant differences between the four different soils were found.

The Scutellospora sp. group showed significantly higher colonization of the poplar roots system in the G-soil than in the other soils (Figure 5d).

Although the poplars grown on the P-soil showed a lower level of AM colonization compared with the C- and G-soils, AM was almost exclusively formed by $G$. intraradices. This suggests that the greater shoot length of the poplars in the P-soil can be attributed to the colonization by G. intraradices. The poplars grown in S-soil differed significantly from the other clones in soils with lower AM colonization, lower presence of $G$. intraradices and $P$. involutus, as well as high abundance of L. tortilis, resulting in the lowest shoot length of all soils. 
Figure 5. AM diversity $((\%)$ in $10 \mathrm{~cm}$ root length) in the four soils originating from different land use types $(\mathrm{C}=$ cornfield, $\mathrm{G}=$ grassland, $\mathrm{P}=$ poplar soil, $\mathrm{S}=$ spruce soil $)$ and the seven poplar clone types: $\mathrm{C} 1=P$. nigra (clone Fritzlar 2 Maserpappel); $\mathrm{C} 2=P$. deltoids; $\mathrm{C} 3=P$. nigra $\times$ P. maximowiczi $($ clone Max 3$) ; \mathrm{C} 4=P$. trichocarpa $; \mathrm{C} 5=P$. maximowiczii; $\mathrm{C} 6=P$. canadensis (clone ROBUSTA); $\mathrm{C} 7=P$. maximowiczii $\times P$. trichocarpa $($ clone Hybrid 275 (NE42).
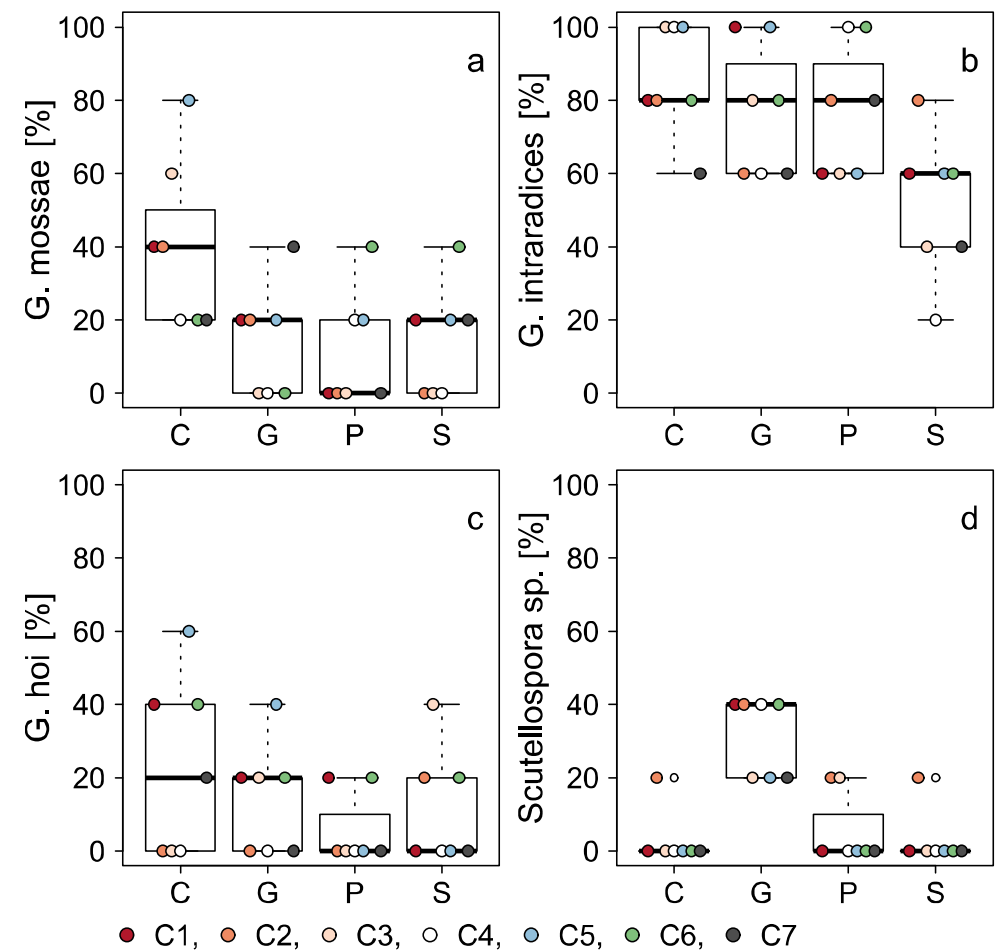

Scutellospora sp. played a major role in G-soil; with highest abundance in clone C2. The establishment of this AM fungi is not well correlated with the shoot length of the poplars. Treseder and Allen [33] showed that Glomus and Scutellospora sp. appeared to have distinct responses to nutrient availability.

\subsection{Influence of the Clone Type}

Between the clone types, differences in AM colonization, shoot length, vesicles, arbuscules and the group of Scutellospora sp. were observed. No significant differences between the poplar clones and the ECM diversity were found (Table 5).

The maximum shoot length was found in the poplar clone $\mathrm{C} 3$, followed by $\mathrm{C} 5, \mathrm{C} 7$ and $\mathrm{C} 2$ (Figure 1C). Clones $\mathrm{C} 1, \mathrm{C} 4$ and $\mathrm{C} 6$ presented the lowest shoot length and respectively colonization rate of AM, vesicles and arbuscules (Figures 1 and 2).

The poplar clones with the greatest shoot length differed significantly from the clones with the lowest shoot length in colonization of AM and number of vesicles (see Table 4). For example, clone C7 presented a significant higher colonization rate of AM, shoot length (Figure 2a,c) and amount of vesicles and arbuscules (Figures $2 \mathrm{a}$ and $3 \mathrm{~b}$ ) in all types of soil. Clone $\mathrm{C} 1$ presented significantly lower amounts of all these factors on all types of soil (Figures 2 and 3). Clone C2 grown in G-soil showed the highest abundance of Scutellospora sp. (Figure 5d, see Table 5). 
Table 5. ANOVA table of the LMMs showing the fixed effect of clone type on the different response variables while accounting for former land use type (C-, G-, P- and S-soil) as a random effect; degrees of freedom $(d f)$ : six between groups and 18 within groups.

\begin{tabular}{cccc}
\hline Response Variable & Transformation & F-Value & $\boldsymbol{p}$-Value \\
\hline AM & - & 8.97 & $<0.001$ \\
ECM & - & 1.47 & 0.2437 \\
Shoot length & - & 32.35 & $<0.001$ \\
AM hyphae & - & 1.55 & 0.218383 \\
Vesicles & - & 18.93 & $<0.001$ \\
Arbuscules & $\log 10+1$ & 14.85 & $<0.001$ \\
Glomus mossae & $\log 10+1$ & 1.10 & 0.40137 \\
Glomus intraradices & - & 0.55 & 0.76256 \\
Glomus hoi & $\log 10+1$ & 2.04 & 0.1132 \\
Scutellospora sp. & $\log 10+1$ & 5.08 & 0.003283 \\
\hline
\end{tabular}

- No transformation performed.

\section{Conclusions}

Although we investigated a relatively small number of samples, we found significant effects regarding the AM and ECM colonization. Under the chosen conditions, poplar clones were initially colonized mostly by $G$. intraradices and subsequently by $P$. involutus. Species of the genus Laccaria can act antagonistic to the AM fungi in this stage of plant development. Our results also indicate that different poplar clone genotypes prefer different AM fungal species. For example the root systems of clone C2 were strongly colonized by Scutellospora sp. in all types of soil. C3 and C5 showed the highest growth rate on poplar soil. Yet, we could not say whether the fungi promoted the poplar shoot length or the fungi were promoted by the fast growing clones because the colonization could either be the consequence of fast host growth or a causal agent of the host growth. Although we only tested $2 \times 5 \mathrm{~cm}$ root length per clone and treatment on arbuscular mycorrhizal colonization, we could assume that arbuscular mycorrhizal colonization density was relatively homogenous on the root system. Our results showed that fungal communities are sensitive to macronutrients and $\mathrm{pH}$. Though the observed abundance of ECM types was highest in slightly acidic substrates, for a successful symbiosis both partners must be able to withstand the lower $\mathrm{pH}$ during all stages of colonization. In summary, the cultivation of poplar on S-soil should be rejected.

Our findings and that of Gehring et al. [8], Khasa et al. [10], Tagu et al. [11,12], van der Heijden and Kuyper [13] and Walker and McNabb [14] imply that both factors, former land use and clone type, are important determinants of mycorrhizal colonization. The land use types represented, beside the abiotic factors, the different inoculum capacities and were therefore the most important factors determining the mycorrhizal abundance and diversity on the roots of poplars. The poplar genotype, however, is affecting the variation of the fungal community on the roots within the given potential of mycorrhizal symbionts. 


\section{Acknowledgments}

This research was financed in the frame of the Fast Wood project, Hann. Münden, Germany.

\section{Author Contributions}

Felicia Gherghel wrote the paper. David Behringer analyzed the data. Stefanie Haubrich and Maren Schlauß performed the ECM and AM experiments under the supervision of Felicia Gherghel, Christina Fey-Wagner selected and provided the poplar clones. Karl-Heinz Rexer designed the study. Alwin Janßen and Gerhard Kost conceived of the project.

\section{Conflicts of Interest}

We affirm that the submitted manuscript contains report of an original work performed in the laboratories of the authors and is not being considered for publication in any other journal. We are not aware of any conflict of interest regarding the work contained in the publication.

\section{References and Notes}

1. Langer, J.; Santner, D.; Krpata, W.J.; Fitz, W.W.; Wenzel, P.; Schweiger, F. Ectomycorrhizal impact on $\mathrm{Zn}$ accumulation of Populus tremula L. grown in metalliferous soil with increasing levels of Zn concentration. Plant Soil 2012, 355, 283-297.

2. Bradshaw, H.D.; Reinhart, C.; Davis, J.; Stettler, R. Emerging model systems in plant biology: Poplar (Populus) as a model forest tree. J. Plant Growth Regul. 2000, 19, 306-313.

3. Brundrett, M.C. Mycorrhizal associations and other means of nutrition of vascular plants: Understanding the global diversity of host plants by resolving conflicting information and developing reliable means of diagnosis. Plant Soil 2009, 320, 37-77.

4. Pullman, G.S.; Cairney, J.; Peter, G. Clonal forestry and genetic engineering: Forest biotechnology-where we stand and future prospects and impacts. Tappi J. 1998, 81, 57-64.

5. Tedersoo, L.; May, T.W.; Smith, M.E. Ectomycorrhizal lifestyle in fungi: Global diversity, distribution, and evolution of phylogenetic lineages. Mycorrhiza 2010, 20, 217-263.

6. Lodge, D.J. The influence of soil moisture and flooding on formation of VA-endo and ectomycorrhizae in Populus and Salix. Plant Soil 1989, 117, 243-253.

7. Molina, R.; Massicotte, H.; Trappe, J.M. Specificity phenomena in mycorrhizal symbioses: Community-ecological consequences and practical implications. In Routledge AMF ycorrhizal Functioning, an Integrative Plant-Fungal Process; Chapman \& Hall, Inc.: New York, NY, USA, 1992; pp. 357-423.

8. Gehring, C.A.; Mueller, C.; Whitham, T.G. Environmental and genetic effects on the formation of ectomycorrhizal and arbuscular mycorrhizal associations in cottonwoods. Oecologia 2006, 149, 158-164.

9. Smith, S.E.; Read, D. Mycorrhizal Symbiosis, 2nd ed; Academic Press: London, UK, 1997.

10. Khasa, P.D.; Chakravarty, P.; Robertson, A.; Thomas, B.R.; Dancik, B.P. The mycorrhizal status of selected poplar clones introduced in Alberta. Biomass Bioenergy 2002, 22, 99-104. 
11. Tagu, D.; Faivre-Rampant, P.; Lapeyrie, F.; Frey-Klett, P.; Vion, P.; Villar, M. Variation in the ability to form ectomycorrhizas in the F1 progeny of an interpsecic poplar Populus spp. Cross. Mycorrhiza 2001, 10, 237-240.

12. Tagu, D.; Bastien, C.; Faivre-Rampant, P.; Garbaye, J.; Vion, P.; Martin, F. Genetic analysis of phenotypic variation for ectomycorrhiza formation in an interspecic F1 poplar full-sib family. Mycorrhiza 2005, 15, 87-91.

13. Van der Heijden, E.W.; Kuyper, T.W. Laboratory experiments imply the conditionality of mycorrhizal benefits for Salix repens: Role of $\mathrm{pH}$ and nitrogen to phosphorus ratios. Plant Soil 2001, 228, 275-290.

14. Walker, C.; McNabb, H.S. Mycorrhizal symbionts associated with hybrid poplars from Iowa, USA. Eur. J. Path 1984, 14, 282-296.

15. Neville, J.; Tessier, J.L.; Morrison, I.; Scarratt, J.; Canning, B.; Klironomos, J.N. Soil depth distribution of ecto- and arbuscular mycorrhizal fungi associated with Populus tremuloides within a 3-year-old boreal forest clear-cut. Appl. Soil Ecol. 2002, 19, 209-216.

16. Danielsen, L.; Thürmer, A.; Meinicke, P.; Buée, M.; Morin, E.; Martin, F.; Pilate, G.; Daniel, R.; Polle, A.; Reich, M. Fungal soil communities in a young transgenic poplar plantation form a rich reservoir for fungal root communities. Ecol. Evol. 2012, 2, 1935-1948.

17. Bahram, M.; Põlme, S.; Kõljalg, U.; Tedersoo, L. A single European aspen (Populus tremula) tree individual may potentially harbuor dozens of Cenococcum geophilum ITS genotypes and hundreds of species of ectomycorrhizal fungi. FEMS Microbiol. Ecol. 2011, 75, 313-320.

18. Karlinski, L.; Rudawska, M.; Leski, T. The influence of host genotype and soil conditions on ectomycorrhizal community of poplar clones. Eur. J. Soil Biol. 2013, 58, 51-58.

19. Gamper, H.A.; Young, J.P.W.; Jones, D.L.; Hodge, A. Real-time PCR and microscopy: Are the two methods measuring the same unit of arbuscular mycorrhizal fungal abundance? Fungal Genet. Biol. 2008, 45, 581-596.

20. Agerer, R. Colour Atlas of Ectomycorrhizae; Einhorn-Verlag: Schwäbisch Gmünd, Germany, 1987-2006.

21. Vierheilig, H.; Coughlan, A.P.; Wyss, U.; Piché, Y. Ink and vinegar a simple staining technique for arbuscular-mycorrhizal fungi. Appl. Environ. Microbiol. 1998, 64, 5004-5007.

22. McGonigle, T.P.; Miller, M.H.; Evans, D.G.; Fairchild, G.L.; Swan, J.A. A new method which gives an objective measure of colonization of roots by vesicular-arbuscular mycorrhizal fungi. New Phytol. 1990, 115, 495-501.

23. Martin, K.J.; Rygiewicz, P.T. Fungal-specific PCR primers developed for analysis of the ITS region of environmental DNA extracts. BMC Microbiol. 2005, 5, doi:10.1186/1471-2180-5-28.

24. NCBI. Available online: http://www.ncbi.nlm.nih.gov/ (accessed on 15 August 2014).

25. UNITE. Available online: http://unite.ut.ee/ (accessed on 15 August 2014).

26. Schwarzott, D.; Schüßler, A. A simple and reliable method for SSU rRNA gene DNA extraction, amplification, and cloning from single AM fungal spores. Mycorrhiza 2001, 10, 203-207.

27. Oksanen, J.; Blanchet, G.F.; Kindt, R.; Legendre, P.; Minchin, P.R.; O’Hara, R.B.; Simpson, G.L.; Solymos, P.; Henry, M.; Stevens, H.; et al. Vegan: Community Ecology Package. R package version 2.0-10. Available online: http://CRAN.R-project.org/package=vegan (accessed on 15 August 2014). 
28. Bates, D.; Maechler, M.; Bolker, B.; Walker, S. lme4: Linear mixed-effect models using Eigen and S4. R package version 1.1-6. 2004. Available online: http://CRAN.R-project.org/package=lme (accessed on 1 October 2014).

29. Hothorn, T.; Bretz, F.; Westfall, P. Simultaneous Inference in General Parametric. Models. Biometr. J. 2008, 50, 346-363.

30. Barker, S.J.; Duplessis, S.; Tagu, D. The application of genetic approaches for investigations of mycorrhizal symbioses. Plant Soil 2002, 244, 85-95.

31. Jumpponen, A.; Jones, K.L.; Mattox, J.D.; Yaege, C. Massively parallel 454-sequencing of fungal communities in Quercus spp. ectomycorrhizas indicates seasonal dynamics in urban and rural sites. Mol. Ecol. 2010, 19, 41-53.

32. Baum, C.; Makeschin, F. Effects of nitrogen and phosphorus fertilization on mycorrhizal formation of two poplar clones (Populus trichocarpa and P. tremula $\times$ tremuloides). J. Plant Nutr. Soil Sci. 2000, 163, 491-497.

33. Treseder, K.K.; Allen, M.F. Direct N and P limitation of arbuscular mycorrhizal fungi: A model and field test. New Phytol. 2002, 155, 507-515.

(C) 2014 by the authors; licensee MDPI, Basel, Switzerland. This article is an open access article distributed under the terms and conditions of the Creative Commons Attribution license (http://creativecommons.org/licenses/by/4.0/). 